\title{
Development of Hybrid Learning Material to Support Object-Oritented Programming Course
}

\author{
Heni Jusuf ${ }^{1}$, Nurdin Ibrahim ${ }^{2}$, Atwi Suparman ${ }^{3}$ \\ $\left\{\right.$ heni.jusuf@civitas.unas.ac.id ${ }^{1}$,nurdin1349@yahoo.com $\left.{ }^{2}\right\}$ \\ Faculty of Science and Engineering, Universitas Nasional Jakarta ${ }^{1}$, Postgraduate Educational \\ Technology, Universitas Negeri Jakarta ${ }^{2}$, Universitas Terbuka \\ Banten $^{3}$
}

\begin{abstract}
This paper was to produce hybrid learning materials that can be used to help students in their efforts to create applications with Object Oriented Programming (OOP). For this purpose, research used qualitative methods using the steps of system approach Model. We note that the performance of students academically was not satisfactory. Their skills to write computer programs are even worst. In this study, Informatics Department students in 2017 who took OOP courses were involved to produce learning material, with the hope that they would improve the competence of students at the global level in the field of computer programming.
\end{abstract}

Keywords: R\&D research, Moodle, System approach, OOP.

\section{Introduction}

The development of computer and internet technology is currently very rapid; this can be seen from the emergence of various types of services that are turning to online. The appearance of the development of the internet makes all the information needed easily and quickly can be obtained. Many individuals are also agencies that carry out their business processes using computer and internet technology. Information Technology has become an integral part of life in modern society. According to the learning theory by [1], that environment shapes behavior, and behavior shapes the environment; this is in line with the current student environment who are accustomed to using information and communication technology devices that have been connected to the internet so that learning materials to be developed are web-based.

The more development of information technology, the need for human resources are higher increasing, and this has encouraged educational institutions to participate by opening informatics study programs; Study program data for Bachelor Degree (S1) as of September 2018 at BAN-PT shows the following results: there are 547 Informatics Engineering study programs, 306 Information Systems study programs, so there are 853 study programs in total.

Seeing the growing trend in the field of information technology, of course, requires a lot of human resources; at present, there are many complaints in the world of work, that graduate competencies are inadequate, even referred to as not relevant to work needs. As in [2] many graduates who are not ready to use, are not prepared to work, as the world wants. As in [3] Students feel that programming concepts are difficult to understand, they think they lack sufficient skills to develop the right computer program; this frustration reduces their 
motivation, and causes many of them to end up with career paths that do not require programming skills.

The absence of the concept of link and match or the relevance of graduate competencies to the needs of graduate users (the world of work) is due to the lack of in-depth study of the competency needs of graduate users at the time the University compiled the curriculum[2]. The study of the basic competencies of graduates of education which are needed by the business world has been carried out in 2012 and 2015,"in the context of developing a competency-based curriculum, with assistance, conducted by the Directorate General of Higher Education data sharing team, the results of a study of 30 collage data samples in the Borneo region, more than $90 \%$ of Universities have compiled a learning curriculum which is not based on a basic competency needs analysis which is needed by graduate users. Universities have set basic competencies in developing learning curriculum only by referring to the curricula of other universities as in [4].

The university is not aware that designing a curriculum cannot directly imitate another university or take it from an existing one because it needs to consider the conditions and character of students who are different from the reference college including determining the amount of credit. If at another university, two credits for object-oriented programming programs, then it does not need two credits at our university, so it needs to have a pattern or strategy in the learning process. During this time, the lecture conditions emphasized cognitive aspects only, so students were less independent in learning, even passive. That is because hidden assumptions still affect lectures, namely the lecturer fully transferred knowledge to the student.

During this time, when students learn, they seem to be objects of the curriculum. As a result, there are learning activities that force students to adjust to the curriculum. Ideally, a curriculum that adapts to the needs of each student, not vice versa, namely students for the curriculum. Students have the right to have the curriculum they want to follow.

Currently, not all graduates of the Information Systems Study Program at Universitas Nasional become programmers; this is because not all students can make computer application products, while programming courses have a considerable portion, namely: Fundamentals of Programming I, three credits; Programming Basics II, three credits; Visual Programming, three credits; Web Design, three credits; Object-Oriented Programming, three credits; Webbased programming I, three credits; Object-oriented Engineering Systems, three credits; Webbased programming II, three credits; Mobile Programming, two credits; Designing e-business, three credits; the total programming courses are as many as twenty-nine credits. If students get into trouble and ultimately do not like programming courses, then it can be ascertained that they will lose as much as twenty-nine credits out of a total of one hundred and forty-four credits.

Current empirical conditions, namely; in 2014, as many as 49 students in the Information Systems study program at the Universitas Nasional had taken object-oriented programming courses, in 2015 there were 59 students, and in 2016 were 45 students, the results obtained for student scores are as shown in Figure 1. 


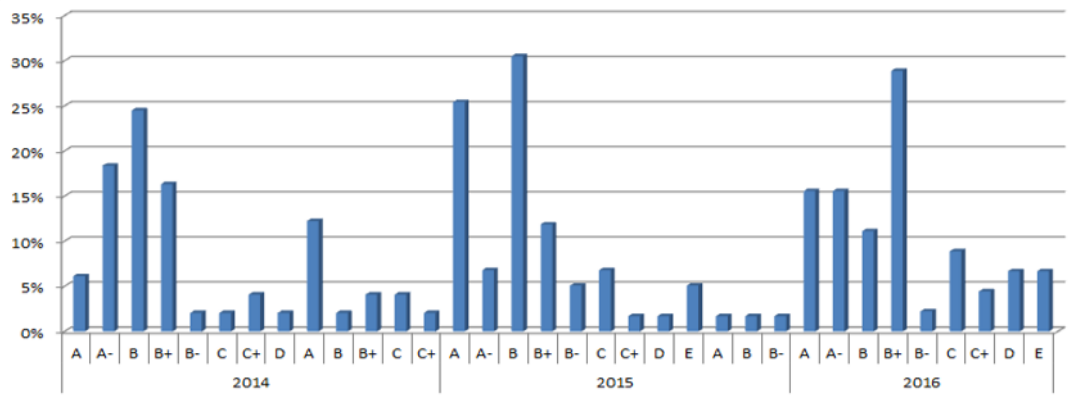

Fig. 1. Precentage of student grades, object-oriented programming courses in the last three years.

From the value data in Figure 1, students who can make object-oriented applications each semester are not more than $25 \%$. The average value/grade obtained by students in each year is not following the quality standards of the Study Program, i.e., 30\% get an A grade or are competent, following the set learning outcomes. The value of students in the last three years for object-oriented programming courses is $29 \%$ get A grade, and $44 \%$ get B grade.

From the problems mentioned above, this has resulted in learning objectives not being achieved, because they do not provide optimal results. If this is left unchecked, then this will result in graduates not being able to compete in the ASEAN and International regions. While graduates from other universities in ASEAN can easily enter to work in Indonesia, for that, it is essential to develop hybrid learning materials, to help and improve the ability of students to make object-oriented application programs in object-oriented programming courses.

Modifications and variations in learning in higher education are by developing learning models based on computer and internet technology. In the world of higher education, the background of learners is very heterogeneous, in the sense that learners not only come from high school graduates but also those who have worked so that with a very heterogeneous learning background, the needs and learning styles of learners also become varied.

Learning model "Hybrid learning" has now become a developing trend as a learning model in universities[5]. This model can be in the form of learning to use the web, teleconference, video conferencing and others. In general, Hybrid learning is web-based learning with an open learning environment accessed through the internet with the aim of facilitating learning and building learner knowledge through meaningful interactions[6]. Some studies showed that the use of the right learning media can accelerate and enhance the interaction between teachers, learners, and instructors; so that the development of learning media becomes a necessity in learning. The choice of a hybrid learning model was to overcome the above problems because based on a survey of internet users, Indonesia occupies the fourth position concerning users who spend a lot of time on the internet.

In general, this study aims to produce products in the form of hybrid learning materials for object-oriented programming subjects. Specifically, this study seeks to: (1) develop a blueprint of hybrid learning materials on object-oriented programming subjects, (2) analyze and describe the responses of content experts to the hybrid learning materials developed, (3) analyze and describe the responses of media experts to the hybrid learning materials developed, (4) analyze and describe the responses of design experts to the hybrid learning materials developed, (5) analyze and describe the responses of students in individual trials to the hybrid learning materials developed, (6) analyze and describe the responses of students in small group trials to the hybrid learning materials developed, (7) analyze and describe 
responses students in field trials on the hybrid learning material developed, (8) analyze and describe the responses of lecturers from object-oriented programming course as users to the hybrid learning materials developed, and (9) implement hybrid learning materials in course of object-oriented programming for $4^{\text {th }}$ semester students in Information Systems Program.

\section{Literature Riview}

Some research results have shown that the effectiveness of learning using Information and Communication Technology is better than traditional or conventional learning concepts. students who use the web in learning had been proven to be twice as fast as their study time compared to classical students, $80 \%$ of these students performed well and were very good, and $66 \%$ of them no need for printed material [7]. Other studies have shown that learning outcomes using computer learning tutorial models and "drill and practice" had been far better than conventional learning.

Learning is a system consisting of various components interconnected with one another. These components include learning objectives, learning resources, methods, media, and evaluation. The definition of learning is "every systematic and deliberate effort to create so that educational activities occur between two parties, namely between learning citizens (students) and learning resources (educators), who conduct learning activities." This definition provides an understanding that learning is not something that happens immediately, but must go through planning first[2]. When we designed, implemented and managed more systematically the learning activities, then the way to improve and enhance the quality of human resources on an ongoing basis will be more visible.

The environment form behaviour and behaviour form the environment. It is in line with the current environment of students who are accustomed to using information and communication technology devices that have been connected to the internet so that the developed learning material is web-based[1]. Learning is the process of progressive behaviour adaptation based on the belief that parents can form a child according to what they want. This is in accordance with the second principle of learning, that is, the behaviour is not only controlled by the response but also under the influence of the conditions or signs contained in the student environment. Learning is that teachers and students simultaneously create an environment including a set of values and beliefs that are considered important for uniting views on the reality of life[8].

The learning experience is obtained through a process of action or experience for oneself on what is learned. Learning consists of active and passive learning. In passive learning, the contribution of reading to master material and memory is $10 \%$, listening to $20 \%$, and contributing to it is $30 \%$. However, active learning when someone says, teaches, demonstrates, or discusses, it can provide $70 \%$ understanding and memory of the mastered material, and if active in carrying out / applying knowledge, it contributes $90 \%$ to our understanding and memory about something[9].

They like the use of multimedia in learning. Learning media that fits the needs is a learning medium that can help teachers and students in the process of 'transfer of knowledge.' The teaching function is to attract the attention of students so that the teaching material to be discussed leads to thoughts, physical and attitude[10]. 


\section{Method}

The R \& D book recommends for development research is to use the System approach model step, which consists of three main stages of the system approach: the identification stage, the stage to develop, the stage to evaluate and revise. The research conducted was R \& $\mathrm{D}$ because it fulfils four main features, namely conducting a preliminary study to find information about developed learning products, developing products based on research results, conducting product trial research developed, and revising products based on trial results so that they become products useful people who answer needs. R \& D research defined as a series of processes that must be carried out in developing and validating educational products, and how to build research steps in the field of educational technology [11]. Development research is an attempt to develop a useful product in the form of learning materials, media, learning strategies for use in schools, not to test the theory[12]. R \& D recommends using a system approach model step consisting of three main stages of the system approach: the identification stage, the stage to develop, the stage for evaluating and revising. The three stages in the procedural model are as shown in Figure 2[11][13].

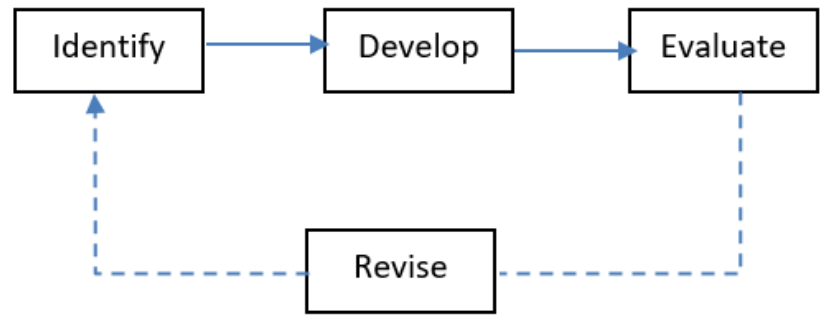

Fig. 2. System approach chart.

The step model system approach includes a procedural system that works with principles, the stage will receive input from the previous stage, and produce output for the next stage so that all components work together to meet and produce effective learning[11].

Learning material is a material or subject matter that is arranged systematically, which is used by lecturers and students in the learning process. If audio, video and computer books or programs contain learning material that is intentionally designed systematically for the learning process sold in the free market, then it can be said that the books and programs are learning materials. The definition of Educational Technology based on AECT in 2004/2008 states that Educational Technology is a study and ethical practice to facilitate learning and improve performance by creating, using, and managing various sources and processes. Educational technology is a complex and integrated process that involves people, procedures, ideas, tools, and organizations to analyze problems, find ways to solve them, apply, evaluate, and manage the resolution of problems involving all aspects of human learning. Development of learning materials can be done by (a) using learning materials that have been used on campus alone or from other campuses by sharing with other teachers; (b) modifying learning materials that exist after the survey is conducted on students based on student learning styles; (c) making new learning materials based on the development of existing teaching materials using different learning strategies. 


\section{Results and Discussion}

Hybrid learning material developed in this study is expected to have a high level of effectiveness and efficiency so that it is suitable to be used as a learning supplement in objectoriented programming subjects. This study uses a development research design called step of system approach with stages, as shown in figure 3.

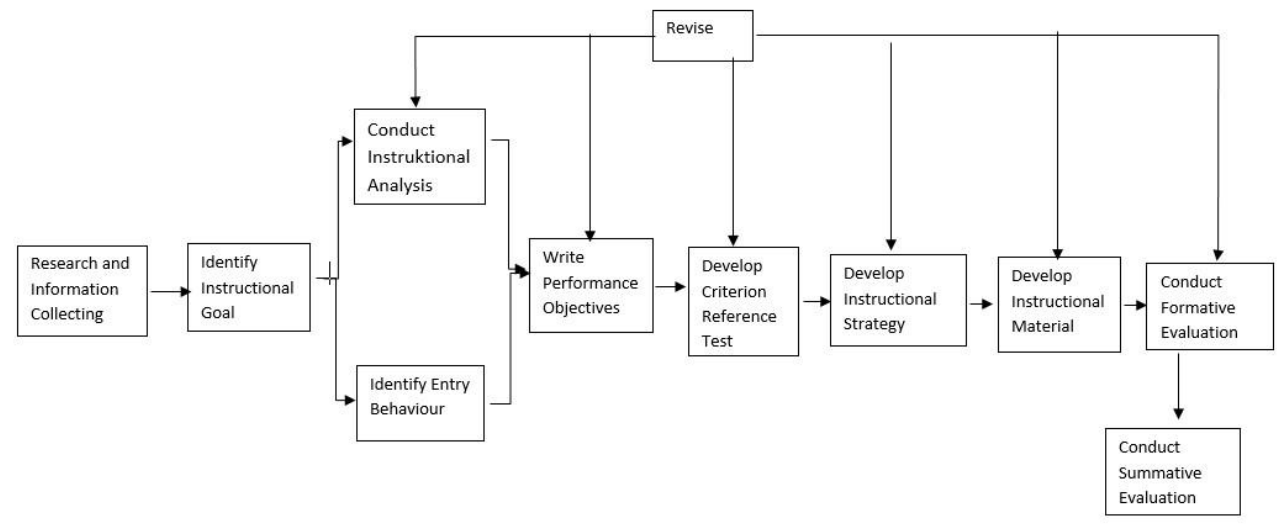

Fig. 3. Step of system approach model.

In this study, it was carried out up to the seventh step, namely doing the formative evaluation. After the product development process is complete, the next step is to conduct a series of trials on product development. The trial consisted of expert trials/validations and field trials. Expert trials/validations consisted of content expert trials, media expert trials, and design expert trials. While the field trials consisted of one on one trials with students, small group trials, and field trials. The results of the validation from the Content Expert from the object-oriented programming course stated that the development product was feasibly implemented in learning. Content experts argue that hybrid learning materials have met the criteria as a medium of self-learning and face-to-face learning regarding the content or linguistic material, and material presentation with excellent qualifications. Content eligibility is feasibility regarding linguistic and overall content structure with a percentage of achievement levels of $97.93 \%$ for online learning materials, excellent specifications.

After completing the trial with the content expert, the next stage is the revision stage 1 following the suggestions for improvement from the content expert. Improvements in the first revision include (1) mechanical repair of errors in spelling and (2) replacement of images in the context of programming learning. The second validation at the initial validation stage is the validation of the learning media expert. The results of validation from instructional media experts give an assessment that multimedia learning has been excellent concerning MOODLE design, text elements, video elements, and hyperlinks elements. Media experts argue that online learning materials are suitable as learning media. Media experts provide improvement suggestions such as: (1) Adding the word "Welcome" to the main page / home to be interesting, (2) Changing menu navigation to a sideways display, (3) Changing the appearance of learning materials in the form of submenus, product feasibility in terms of Online learning 
materials obtain $93 \%$ percentage of achievement levels for online learning materials, and are very well qualified.

After completing the trial with media experts, the next stage is the revision of $2^{\text {nd }}$ phase following the recommendations of improvements from media experts. Improvements in the $2^{\text {nd }}$ phase revision include: (1) Adding the word "Welcome," (2) improving the appearance of the navigation menu, (3) improving the appearance of learning materials into submenus. The $3^{\text {rd }}$ expert validation is the validation of learning design experts. The results of the validation of the learning design expert commented that the hybrid learning material was excellent and suitable for use in learning. Feasibility concerning learning design includes feasibility regarding the instructional design interface. Assessment from the design expert obtains a percentage of achievement levels for hybrid learning materials by $92 \%$ and is in excellent qualification.

After completing the trial to the design expert, the next stage is the revision of $3^{\text {rd }}$ stage according to input from the learning design expert. The revisions include: (1) replacing several main page titles into Indonesian, (2) replacing the term learning material into learning tools, and (3) increasing time allocation to adjust learning outcomes. After completing the initial trial/expert validation, then conduct the first field trial for each student. Individual trials on three students who had high, medium and low abilities. The results obtained from individual trials of hybrid learning materials capture a percentage of achievement levels of $81 \%$ and are in excellent qualifications. The second field trial was a small group trial with a total of six students with two high-achieving students, two moderate learning students, and two lowachieving students. The results of small group trials of hybrid learning materials obtain a percentage level of achievement of $79.17 \%$ and are in proper qualifications. The fourth field trial was a field trial (ten students). The results of this field trial obtained results for hybrid learning materials amounting to $83.17 \%$ and proper qualifications. After completing the field trial, the final step in the design of this development is revision stage 3, or improvement of operational products. The improvement was carried out based on input from respondents during the field trial.

\section{Conclusions}

This research was research on the development of R \& D, using a system approach step. Based on several evaluation results, then: object-oriented programming subjects can use hybrid learning material; Object-oriented programming subjects are subject to expertise so that independent and face-to-face learning can apply hybrid learning material as a supplement; Hybrid learning materials are developed based on the competency units in the SKKNI (Indonesian National Work Competency Standards) Software development in the hope that if students pass this course, students are ready to take an object-oriented programming competency test in a professional certification institution, as one of their programming skills.

Acknowledgments. Thanks to DRPM for funding this research, thanks to LPPM UNAS dan Thanks to Anonimous reviwer. 


\section{References}

[1] "Bandura_SocialLearningTheory.pdf.".

[2] M. A. Suparman, Desain Instruksional Modern. Jakarta: Erlangga, 2014.

[3] S. Alhazbi and L. S. Ismail, "Supportive online learning environment to improve students' satisfaction in object-oriented programming courses," in 2010 2nd International Congress on Engineering Education, 2010, pp. 89-93.

[4] B. STMIK Banjar Baru, "Model Sistem Informasi Pemetaan Kompetensi dasar bidang Teknologi Informasi sebagai pendukung dalam mendesain sistem kurikulum pembelajaran di Perguruan Tinggi Banjarmasin, STMIK Banjarbaru [Bahar., 2016, Basic Competency Mapping Information System Model of Information Technology field, as a supporter in designing learning curriculum systems at Banjarmasin College, STMIK Banjarbaru.]." 2016.

[5] R. M. Bernard, E. Borokhovski, R. F. Schmid, R. M. Tamim, and P. C. Abrami, “A meta-analysis of blended learning and technology use in higher education: from the general to the applied," J. Comput. High. Educ., vol. 26, no. 1, pp. 87-122, Apr. 2014.

[6] R. McGloin, K. T. McGillicuddy, and J. L. Christensen, "The impact of goal achievement orientation on student technology usage in the classroom," J. Comput. High. Educ., vol. 29, no. 2, pp. 240-266, Aug. 2017.

[7] D. K. Rusman and Cepi R, Information and Communication Technology-based Learning. Jakarta: Rajawali Press, 2011.

[8] M. J. Hannafin and K. L. Peck, The design, development, and evaluation of instructional software. New York : London: Macmillan; Collier Macmillan, 1988.

[9] J. E. Dugan, "Audio-Visual Methods in Teaching, Revised Edition, by Edgar Dale. The Dryden Press, 520 pp. \$6.25,” Educ. Forum, vol. 19, no. 2, pp. 244-244, Jan. 1955.

[10] H. Jusuf, "Model Blended Learning Berbasis Teknologi Informasi Dalam Pembelajaran Algoritma Dan Pemrograman," JUTISI, vol. 6, no. 2, pp. 1459-1466, Jan. 2018.

[11] M. D. Gall, J. P. Gall, and W. R. Borg, Educational research: an introduction, 8th ed. Boston: Pearson/Allyn \& Bacon, 2007.

[12] L. R. Gay, G. E. Mills, and P. W. Airasian, Educational research: competencies for analysis and applications, 10th ed. Boston: Pearson, 2012.

[13] A. Januszewski, M. Molenda, and Association for Educational Communications and Technology, Eds., Educational technology: a definition with commentary. New York, NY: Lawrence Erlbaum Associates, 2008. 